\title{
GREAT GAP BETWEEN CUSTOMERS' TASTE AND MARKET VARIETY IN THE CAR MARKET IN IRAN
}

\author{
S. F. Mousavi ${ }^{1 *} \&$ B. Vizvari ${ }^{2}$ \\ Department of Industrial Engineering \\ Eastern Mediterranean University, TRNC \\ ${ }^{1}$ farhad. mousavi@cc.emu.edu.tr, 2bela.vizvari@emu.edu.tr
}

\begin{abstract}
In this paper, types of cars are described by factors, with each factor consisting of different levels. The satisfaction of the customer is determined by the levels of the factors and the price of the car. Two groups of customers with different tastes are identified in the car market in Iran. The two groups cover 82.4 per cent of customers. Based on the values of the factors, the value of each vehicle is obtained for each group. The aim of this research is to obtain a better understanding of customers' taste, in order to determine the market share of cars and ensure that customers' needs can be satisfied properly. In this way, companies can develop better strategies and production plans and can increase their market share. The size of each group was determined, as well as their characteristics in terms of gender, age, and education status. Using Tirole's [27] and Gabszewicz and Thisse's [12] respective theories, the shares of the car market, according to customers' demands, were determined. The new method adopted in this study is the generalisation of Tirole's [27] product differentiation theory to the case in which the pairwise ranking of the products forms an acyclic network and not only a directed path. The estimated demand is compared with the sales data from the last five years. A big gap between the status of the vehicle sales and the customer requirements is observed in the car market in Iran.
\end{abstract}

\section{OPSOMMING}

Hierdie studie beskryf voertuie met verskillende faktore wat uit meerdere vlakke bestaan. Die kliënt tevredenheid word bepaal deur die vlakke van die faktore en die voertuig se prys. Twee kliëntgroepe met verskillende voorkeure is in die voertuigmark in Iran geïdentifiseer. Die twee groepe beslaan 82.4 persent van die kliënte. Gegrond op die waardes van die faktore word die waarde van elke voertuig vir elke groep bepaal. Die doel van hierdie navorsing is om beter kliënt voorkeure te verstaan om sodoende die markaandeel van die voertuie te bepaal en dus aan die kliëntebasis se vereistes beter te voldoen. Met hierdie inligting kan vervaardigers beter strategieë en produksie planne beraam en sodoende hul markaandeel vergroot. Elke groep is bepaal gegrond op hul eienskappe soos geslag, ouderdom en opvoeding. Tirole en Gabszewicz en Thisse se teorieë is gebruik om die markaandeel volgens die kliënte se vereistes te bepaal. Hierdie navorsing se bydrae is ' $n$ veralgemening van Tirole se produk differensiasie vir die geval waar die paargewyse rangskikking van produkte ' $n$ asikliese netwerk vorm. The beraamde vraag is vergelyk met verkoopsdata van die laaste vyf jaar. ' $n$ Groot gaping tussen die voertuigverkope en die kliënte vereistes in Iran is waargeneem.

\footnotetext{
${ }^{1}$ Author was enrolled for a PhD (Industrial Engineering) degree in the Department of Industrial Engineering, Eastern Mediterranean University

* Corresponding author
} 


\section{$1 \quad$ INTRODUCTION}

Various authors have worked on the empirical analysis of customer behaviour. Earlier researchers such as Cubbin [8] examined some aspects of pricing behaviour in the UK car industry, while Murray and Sarantis [23] applied an extended version of the superior goods model to the UK car market. Recently, the Economics for the Environment Consultancy (EFTEC) [11] published a report that aimed to understand how various attributes determine households' new car purchasing decisions. They estimated a model of choice behaviour that predicts the market share that a vehicle will command, based on its attributes, in the United Kingdom [11].

Determining the utility function based on criteria factors to explain customers' behaviour and to satisfy their needs is an interesting area that many authors have addressed - for example, Flavio and Rangel [1] in the case of real estate [1].

Rahmati and Yousefi [2] investigated the behaviour of two major companies, Iran Khodro Co. (IKCO) and Saipa, who together hold 98 per cent of the total market share in Iran [2]. Their results support the hypothesis that manufacturers are charging high mark-ups, and the view that both firms prefer to operate with lower quality rather than higher quality production. Rahmati and Yousefi's [2] computations, which provided these findings, are based on one year: 2005. IKCO abandoned its oldest and second-best-selling car model, the Peykan, in 2006 because of environmental issues. The company has since added ten new models to its product basket that belong to the higher price category, in order to cover the needs of customers. The analysis of our research uses five years' data (2007-2012) to confirm the findings of our approximation.

Customers' purchasing behaviour is tested by comparing car models. Selected customers are questioned directly about their tastes. In each choice, a customer selects one model out of two. Customers' behaviour is then reconstructed based on their answers, covering the whole car market in Iran. Knowing the customers' car selection behaviour, it is possible to predict the response of the market to changes in the physical and cost attributes of the vehicles.

A linear approximation is used in this study for the utility function of customers of the Iranian car maker IKCO. The result of our analysis is that there is a huge gap between the customers' taste and the current range of choice in the Iranian car market. For the purposes of our analysis, we simplify the undoubted complexity of customers' behaviour into a utility function. In effect, this utility function describes a score for each option, attributing a higher score to options that provide a greater surplus of advantages overall. The value of the utility function depends on the attributes of the car and the way in which the customer selects a car. Here it is sufficient to note that this analysis accounts for customer income, vehicle purchase price, and a host of other attributes describing the physical appearance and motoring capabilities of a vehicle.

A mathematical model to achieve the highest consumer utility function based on Tirole [27] and price as a function of quality as presented by Gabszewicz and Thisse [12] is used as the theoretical basis of this research.

This paper is outlined as follows: Section 2 presents a review of relevant literature, while Section 3 provides a discussion of the attributes of cars and their numerical values, and the questionnaires used in this study to test customers' behaviours. In Section 4, the mathematical models required to determine customers' preferences are presented and the numerical approximation of the utility function is determined. The estimated demand is determined in Section 5, which also presents the method that was followed, which is the generalisation of Tirole's [27] product differentiation theory to the case in which the pairwise ranking of the products forms an acyclic network, not only a directed path. The paper finishes with some discussion and conclusions in Sections 6 and 7. 


\section{LITERATURE REVIEW}

\subsection{Utility}

'Utility', which means usefulness and benefits, is an important concept in economics and decision theory. Utility can be interpreted as the ability of goods and services to satisfy the customer's needs.

'Desires' cannot be measured directly, as has been already proposed; but they can be measured indirectly. The measure is found in the price that a person is willing to pay for the performance or satisfaction of his/ her desire [22].

Dizaj i [10] refers to economists J ones and Marshall, who argue that utility is measurable, and that it can be measured numerically by a unit called the 'utile'. They believed that utility is measurable and even additive; that is, the utility obtained from the consumption of two goods can be gathered together. Dizaji [10] also refers to economists Fisher and Worth, who opposed the numeric utility theory, because they believed that utility is a perceived value obtained while comparing consumed goods or services in one place with consumed good or services in another place. They argued that utility is measurable, but not additive.

Utility functions are used to model and analyse human behaviour indirectly. These models are often uniform and quasi-concave. Moreover, "it is possible that the preferences are not representable by a utility function. An example is lexicographic preferences which are not continuous and cannot be represented by a continuous utility function" [16].

Lancaster [19] suggested that utility is derived from both positive and negative characteristics.

\subsection{Utility for money}

A utility function has various uses or applications, but utility expressed in money is used frequently, especially in economics. There are various properties of the utility function for money, including:

- Boundedness: it is bounded about the origin, which shows that beyond a given point, the relevance (usefulness) of money ceases; an example is the size of an economy that is bounded at any time.

- Asymmetry: the utility function for money is also symmetric about the origin. This shows the varying implications that money has on a business or person; these implications can be positive (gain) or negative (loss).

- Nonlinearity: where utility expressed in money is influenced by various outcomes of choices to obtain the optimal outcome will depend on other possible decision outcomes for the same period of time.

- $\quad$ Concave: the utility function for money shows diminishing marginal utility, as it lies in the positive region; it is thus concave [5].

\subsection{Customer satisfaction and behaviour in the automotive industry}

Customer satisfaction and behaviour is determined by using effective evaluation instruments to judge the perceptions of actual performance, and by understanding the experience and satisfaction of customers' judgments [20]. Consumers' quality expectation levels have risen as they have gradually become more knowledgeable and sophisticated [17].

Rahmati and Yousefi [2] used the logit method to characterise customer behaviour in the Iranian car market. Their models failed, however, to give reasonable explanation of the substitution patterns between different choices in the models. In their calculations, the utilities were described as a function of attributes of choices. 
Considering that customers' knowledge and needs give car dealers a competitive advantage [7], it is important for dealers to understand that their good or bad performances will affect customer behaviour [25]. In an empirical study using Mitsubishi drivers in the Netherlands, dealer relationships (rather than price) represented a very important decisionmaking variable for customers when buying a car [13]. Safety, vehicle performance, and the quality of parts and repairs were introduced as the most effective criteria that influence customer satisfaction levels in the Iran automobile market [4].

Factors that typically influence a customer's satisfaction with a product include the product's durability, whether it offers value for money, the product's ease of use, and certain technical aspects $[18,21]$. Other influential characteristics may include the interior quality of the car, the easy setup and use of the panel, and the quality of the driving experience [15].

In the sales sector, an investigation was conducted at Fiat in Italy into satisfaction among car buyers in two areas: satisfaction with the purchase, and satisfaction with the delivery [26]. In addition, the influence of the selling behaviours of the sales people on customer satisfaction with products was reviewed. The findings indicated that customer satisfaction with a dealer is negatively related to a sales orientation and positively related to a customer orientation [14]. Based on the theory of consumer behaviour, Abounoori and Rezvani [3] estimated that the 'safety' variable was the most important factor affecting the price of automobiles in Iran [3].

Finally, the after-sales service satisfaction is frequently considered to be a dimension that is usually associated with overall customer perceptions of service quality and assessment with the service providers [24]. In a study conducted in the German automotive industry, a big gap between the expected level of service and the perceived quality was an indicator, for management, to improve customer satisfaction [9].

To obtain customer needs and recognise their requirements, Botha et al. [6] concluded that the best approach would be based on individual, face-to-face interviews and surveys.

\section{RESEARCH METHODOLOGY}

\subsection{Selection factors}

All products have a series of qualitative and quantitative specifications; any change in the levels of factors and different combinations of the factor levels represent a different variety of the final product.

In this study, the cars are described using 11 factors (parameters or attributes). Each parameter has several finite values. The utility function is tested on realistic combinations of these values. In the next step, we use paired comparison to identify the best choices, based on the customers' point of view.

The nominated factors are:

1. Price: this factor is one of the most important when selecting and buying a car. Here, price is categorized to the five classes.

2. Car size: small, medium, and large.

3. Engine capacity: less than $1500,1500-2000$, and more than $2000 \mathrm{cc}$.

4. Body design: hatchback, sedan, and SUV.

5. Gearbox: manual and automatic.

6. Fuel type: petrol and hybrid.

7. Fuel consumption: low and medium.

8. Car acceleration: medium and high. 
9. Options: simple, medium, and full. (Simple means a car without features such as air conditioning and hydraulic steering; medium means a car with equipment such as electric windows, air conditioning, and hydraulic steering, but without options such as air bags or cruise control.)

10. Boot size: small, medium, and large.

11. Passenger capacity: either four or five people.

Table 1 gives the possible values of these 11 factors.

Table 1: Car factors and related levels

\begin{tabular}{|c|c|c|c|c|c|c|c|c|c|c|}
\hline$\frac{\Xi}{\xi}$ & Ñ & 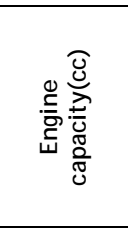 & $\begin{array}{l}5 \\
\frac{5}{7} \\
8 \\
\frac{7}{8} \\
8\end{array}$ & $\begin{array}{l}\frac{x}{8} \\
\frac{8}{10} \\
8\end{array}$ & $\sum_{\frac{0}{0}}^{\frac{8}{2}}$ & 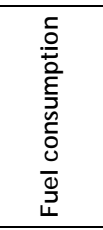 & 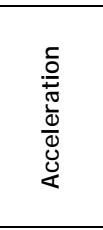 & $\frac{\frac{n}{0}}{\frac{0}{\sigma}}$ & 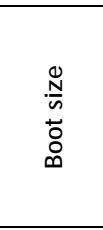 & 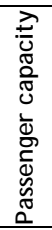 \\
\hline$<10$ & Small & $<1500$ & H-back & Manual & Petrol & Low & Medium & Simple & Small & 4 \\
\hline $10-15$ & Medium & $1500-2000$ & Sedan & Automatic & Hybrid* & Medium & High & Medium & Medium & 5 \\
\hline $15-20$ & Large & $>2000$ & SUV & & & & & Full & Large & \\
\hline $20-30$ & & & & & & & & & & \\
\hline$>30$ & & & & & & & & & & \\
\hline
\end{tabular}

Note: Each unit for the 'Price' factor is in 1,000 US\$ (e.g., $<10$ is $<10,000$ US\$).

\subsection{Conversion of qualitative parameters into quantitative parameters}

All the values in Table 1 appear in the current model range of IKCO. For factors which have two levels, such as gearbox type, fuel type, or fuel consumption, zero and one are used to change the qualitative parameters to quantitative parameters. Table 2 shows the numerical representations of the values that were given in Table 12:

Table 2: Quantitative values for the car factors

\begin{tabular}{|c|c|c|c|c|c|c|c|c|c|c|}
\hline$\frac{d}{d}$ & $\frac{N}{n}$ & 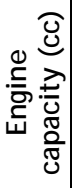 & $\begin{array}{l}5 \\
0 \\
\frac{9}{8} \\
\frac{7}{8} \\
8\end{array}$ & $\begin{array}{l}\frac{x}{8} \\
\frac{8}{7} \\
8 \\
\end{array}$ & $\frac{8}{\frac{8}{2}}$ & 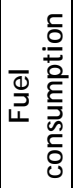 & $\begin{array}{l}\frac{5}{0} \\
\frac{0}{0} \\
\frac{0}{0} \\
\frac{0}{d} \\
\frac{d}{4}\end{array}$ & $\frac{n}{\frac{0}{0}}$ & 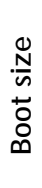 & 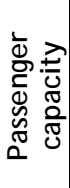 \\
\hline 7.5 & 1 & 1.4 & 1 & 0 & 1 & 1 & 0 & 1 & 10 & 4 \\
\hline 12.5 & 2 & 1.7 & 2 & 1 & 0 & 0 & 1 & 2 & 13 & 5 \\
\hline 17.5 & 3 & 2.5 & 3 & & & & & 3 & 15 & \\
\hline \multicolumn{11}{|l|}{22.5} \\
\hline 35 & & & & & & & & & & \\
\hline
\end{tabular}

\subsection{Availability and possible options of cars}

Twenty-seven cars are defined by combining the values of the factors such that all the combinations make sense and can be produced in reality. As a matter of fact, only eight of the combinations do not exist in the current product basket of the company. Three further models have been produced, and another model is in the launch phase. Even these twelve models could be produced in the future if their production seemed to be economical. The twenty-seven models are distributed across five categories according to the price of the cars, as shown in Table 3. The underlined numbers are cars that do not exist in the current product basket. 
Table 3: Twenty-seven cars in five price categories

\begin{tabular}{|c|c|c|c|c|c|c|}
\hline Price & \multicolumn{7}{|c|}{ Car models } \\
\hline$<10$ & $\underline{1}$ & $\underline{2}$ & $\underline{3}$ & 4 & $\underline{5}$ & $\underline{6}$ \\
\hline $10-15$ & 7 & 8 & $\underline{9}$ & 10 & $\underline{11}$ & 12 \\
\hline $15-20$ & $\underline{13}$ & 14 & 15 & $\underline{16}$ & 17 & 18 \\
\hline $20-30$ & 19 & 20 & 21 & 22 & $\underline{23}$ & 24 \\
\hline$>30$ & $\underline{25}$ & 26 & $\underline{27}$ & \multicolumn{4}{|c}{} \\
\cline { 1 - 2 } & & &
\end{tabular}

\subsection{Testing customers' behaviours}

A survey was carried out with selected customers, and fieldwork was conducted to investigate customers' behaviour and to identify their interests and preferences when choosing a vehicle that meets their criteria. The main tool used was a questionnaire that was designed for this purpose. The questionnaire that the customers were asked to complete is based on paired comparisons between vehicles.

Each questionnaire contains four pairs; after asking the customers to fill in basic information such as gender, age, and education level, they were asked to choose the car that is most compatible with their preferences (see the Appendix).

In this study, only models belonging to the same price category or two consecutive categories were compared. There are 189 comparable pairs. Each pair used is repeated for example, both $(1,2)$ and $(2,1)$ can be considered. A model cannot be compared with itself.

Because of customer diversity, five copies of each questionnaire were distributed randomly and customers were asked to answer it. Each pair of models was evaluated by five customers. A model is considered to be preferable to another one if at least four out of the five customers prefer it. For example, in comparing Model No. 2 and Model No. 5, all five customers chose Model No. 5 , which means that No. 5 is the winner in this comparison. In comparing Model No. 1 and Model No. 8, four customers selected No. 1, which means that No. 1 is the winner. Altogether, 57 winners were obtained in this way.

\section{MATHEMATICAL MODELLING}

The following notations are used throughout the paper:

$\mathrm{P}=$ the number of parameters

$\mathrm{W}_{i}=$ the weight of the parameter $i$ (this is a variable of the model)

$\mathrm{P}_{i j}=$ the value of the parameter $i$ in the car of type $j$ (this is a fixed value discussed above; see Table 2)

The scores of cars are supposed to be a linear function of the parameters:

$$
\mathrm{L}_{j}=\Sigma \mathrm{W}_{i} \mathrm{P}_{i j}
$$

The first step is to find the weights of the parameters, i.e., the $\mathrm{W}_{i}$ values. Based on those, we can then define the score values of the cars, i.e., the $\mathrm{L}_{j}$ values. The value of the utility function is discussed below.

If a model is the winner over another model, then its score must be greater than that of the other model. The minimal difference in the score is claimed to be at least $\Delta$, where $\Delta$ is a positive constant. Assuming that model $j$ is the winner over model $k$, then the weights must satisfy the linear inequality:

$$
\mathrm{L}_{k}+\Delta=\Sigma \mathrm{W}_{i} \mathrm{P}_{i k}+\Delta \leq \mathrm{L}_{j}=\sum \mathrm{W}_{i} \mathrm{P}_{i j}
$$


Two main issues are involved in building a score function:

1. The constraints of type (1) must be consistent, i.e., they may not contain any contradiction.

2. If the constraints of type (1) are consistent, then there are an infinite number of $\underline{\mathrm{W}}$ vectors that satisfy all the constraints, with the exception of some very unlikely degenerated cases. If there are an infinite number of $\underline{\mathrm{W}}$ vectors, then a robust one must be selected. Generally, a vector is considered more robust if it is not on the surface of the polyhedral set defined by type (1) constraints.

\subsection{Elimination of contradictions}

Let $E$ be the set of pairs such that there is a winner in the above-mentioned sense. If $(j, k)$ are in $E$, then model $j$ is the winner over $k$. Let $V$ be the set of the 27 models. Obviously, the directed graph $G(V, E)$ may not have directed circuits, as any directed circuit represents a contradiction.

Unfortunately, the answers of the customers contain several contradictions. Thus, some (winner, loser) pairs must be disregarded. In order to lose as little information as possible, the number of disregarded pairs must be minimised. This problem is solved by the integer programming problem:

$$
\begin{gathered}
\operatorname{Min} \sum y_{j k} \\
(j, k) \in E \\
\text { s.t } \mathrm{L}_{k}+\Delta \leq \mathrm{L}_{j}+M y_{j k} \\
(j, k) \in E \\
\\
\forall i:-1 \leq \mathrm{W}_{i} \leq 1 \\
y_{j k} \text { is binary, }
\end{gathered}
$$

where $M$ is a large positive number and $\Delta$ is a small positive number.

The lower and upper bounds of the $\mathrm{W}_{\mathrm{s}} \mathrm{s}$ give the $l_{\infty}$ normalisation of the $\mathrm{W}$ vector. Normalisation must be applied, otherwise some optimisation problems mentioned below would be unbounded. $l_{\infty}$ normalisation is one of the simplest options. Let $y^{*}$ be the optimal solution of the problem and $\mathrm{F}=\left\{\left((j, k) \mid y_{j k}^{*}=1\right)\right\}$. If $y_{j k}^{*}=1$, then the term $\mathrm{M}$ helps to satisfy the constraint of type (1) concerning the $(\mathrm{j}, \mathrm{k})$ pair. The objective function is the minimisation of the number of this type of help. Thus, the value of the $\mathrm{W}_{i} s$ can be determined on the set of $E \backslash F$. The suggested optimal solution disregards 12 pairs.

\subsection{Determination of a robust solution}

If the contradictions are eliminated, then the remaining inequalities of constraints (1) determine a polyhedral set.

The determination of a robust solution is carried out in two main steps. In the first one, only a feasible solution is determined. In the second step, it is shifted into the interior of the polyhedral set.

\subsubsection{Step 1. Generation of a feasible solution}

To determine a feasible vector $\mathrm{W}$, the following linear programming problem is solved:

$$
\begin{gathered}
\text { Min } \sum \mathrm{W}_{i} \\
i=1 \\
\text { s.t } \mathrm{L}_{k}+\Delta \leq \mathrm{L}_{j} \\
\mathrm{~L}_{j}, \mathrm{~L}_{k} \geq 0 \\
(j, k) \in \mathrm{E} \backslash \mathrm{F} \\
\forall i:-1 \leq \mathrm{W}_{i} \leq 1
\end{gathered}
$$

The linear programming problem gives a basic feasible solution; it is an extreme point of the polyhedral set. Thus it is on the surface of the set. The objective function of problem (2) has no special importance, as the feasible set of (2) is bounded because of the 
normalisation. After solving the problem, a feasible solution is achieved by the following $\mathrm{W}_{\mathrm{i}} \mathrm{s}$ :

Table 4: The values of the factors for Customer Group 1

\begin{tabular}{|c|c|c|c|c|c|c|c|c|c|c|}
\hline $\mathbf{W}_{\mathbf{1}}$ & $\mathbf{W}_{\mathbf{2}}$ & $\mathbf{W}_{\mathbf{3}}$ & $\mathbf{W}_{\mathbf{4}}$ & $\mathbf{W}_{\mathbf{5}}$ & $\mathbf{W}_{\mathbf{6}}$ & $\mathbf{W}_{\mathbf{7}}$ & $\mathbf{W}_{\mathbf{8}}$ & $\mathbf{W}_{\mathbf{9}}$ & $\mathbf{W}_{\mathbf{1 0}}$ & $\mathbf{W}_{\mathbf{1 1}}$ \\
\hline-0.054 & 0.1 & 0.833 & 0.11 & -0.1 & 0.109 & 0.26 & -0.04 & 0.26 & -0.02 & -0.021 \\
\hline
\end{tabular}

The reason for some negative $\mathrm{W}$ values is the essence of those parameters; for example, price, fuel type, fuel consumption, and car acceleration have negative values that are interpretable by their nature and customer taste.

\subsubsection{Step 2. Find an interior point in the polyhedral set}

In Step 1, an optimal feasible solution is found on the surface of the set; this extreme point is determined by the active constraints. The role of Step 2 is to find a robust solution. It is obtained by shifting the extreme point into the interior of the polyhedral set. To achieve this purpose, first a direction $\mathrm{f}$ showing the middle of the polyhedral set is obtained, and then one step moving in that direction is needed. The optimal solution satisfies the active constraints by equation and all the other constraints by strict inequalities. Let $I$ be the set of active constraints; if $\mathrm{i} \in I$ then $a_{i}$ is the left-hand side vector of the active constraints. If an interior point exists, then it satisfies all the constraints with strict inequality. The interior point is obtained in the form $W+\lambda \underline{f}$, where $\lambda>0$ is a real number and the direction $f$ satisfies the inequalities

$$
\forall i \in I: a_{i} f<0 .
$$

In some cases, $\underline{\mathrm{f}}$ can be computed by the formula: $f=\sum_{i \in I} \frac{a_{i}}{\left\|a_{i}\right\|}$.

However, this does not work in all cases. If so, then let $\varepsilon>0$ be a small positive number. If $l_{\infty}$ normalisation is used, then a feasible solution of the constraint set

$$
\begin{aligned}
& \forall i \in I: \frac{a_{i} f}{\left\|a_{i}\right\|} \leq-\varepsilon \\
& \forall j:-1 \leq f_{j} \leq 1
\end{aligned}
$$

must be obtained. This second method had to be applied in the case of Customer Group 1.

Table 5: $f$ values for active constraints

\begin{tabular}{|c|c|c|c|c|c|c|c|c|c|c|}
\hline $\mathbf{f}_{\mathbf{1}}$ & $\mathbf{f}_{\mathbf{2}}$ & $\mathbf{f}_{\mathbf{3}}$ & $\mathbf{f}_{\mathbf{4}}$ & $\mathbf{f}_{\mathbf{5}}$ & $\mathbf{f}_{\mathbf{6}}$ & $\mathbf{f}_{\mathbf{7}}$ & $\mathbf{f}_{\mathbf{8}}$ & $\mathbf{f}_{\mathbf{9}}$ & $\mathbf{f}_{\mathbf{1 0}}$ & $\mathbf{f}_{\mathbf{1 1}}$ \\
\hline-0.199 & 0.746 & 1 & 0.135 & 1 & 1 & 0.388 & 0.580 & 1 & -0.009 & 0.223 \\
\hline
\end{tabular}

Let $\mathrm{H}$ be the hyperplane defined by the linear equation $c x=d$, where $c$ and $x$ are $n$ dimensional vectors and $d$ is a real number, i.e., $H=\{x \mid c x=d\}$. Let $y$ be any $n$-dimensional vector. It is well known that the signed distance of $\mathrm{y}$ from $\mathrm{H}$ is: $\frac{c}{\|c\|} y-\frac{d}{\|c\|}$.

Let $h$ be a lower bound for all the distances of the vector $W+\lambda f$ from all the constraints of the above-mentioned polyhedral set. To determine $h$ and $\lambda$, the following linear programming problem must be solved:

$$
\frac{\boldsymbol{a}_{j, k}}{\left\|\boldsymbol{a}_{\boldsymbol{j}, \boldsymbol{k}}\right\|}(W+\lambda \mathrm{f})-\frac{\Delta}{\left\|\boldsymbol{a}_{j, k}\right\|} \leq-h \text { for all }(j, k) \in E \backslash F \text { with } \boldsymbol{a}_{\boldsymbol{j}, \boldsymbol{k}}=L_{j}-L_{k}
$$

To determine the signs in the constraints, the fact that the normal vectors of the constraints show out of the set must be taken into consideration. The optimal values of $h$ and $\lambda$ are 0.3234 and 0.0533 , respectively. The robust point is chosen as $W^{*}=W+\lambda f$, where $W$ is the optimal solution of problem (2).

Table 6: $\mathrm{W}_{i}^{*}$ value

\begin{tabular}{|c|c|c|c|c|c|c|c|c|c|c|}
\hline $\mathbf{W}_{\mathbf{1}}^{*}$ & $\mathbf{W}_{\mathbf{2}}^{*}$ & $\mathbf{W}_{\mathbf{3}}^{*}$ & $\mathbf{W}_{\mathbf{4}}^{*}$ & $\mathbf{W}_{\mathbf{5}}^{*}$ & $\mathbf{W}_{\mathbf{6}}^{*}$ & $\mathbf{W}_{\mathbf{7}}^{*}$ & $\mathbf{W}_{\mathbf{8}}^{*}$ & $\mathbf{W}_{\mathbf{9}}^{*}$ & $\mathbf{W}_{\mathbf{1 0}}^{*}$ & $\mathbf{W}_{\mathbf{1 1}}^{*}$ \\
\hline-0.064 & 0.139 & 0.886 & 0.117 & -0.046 & 0.162 & 0.280 & -0.009 & 0.3133 & -0.0205 & -0.009 \\
\hline
\end{tabular}


Table 7: The score values of the cars based on $W_{i}^{*}$

\begin{tabular}{|c|c|c|c|c|c|c|}
\hline Car & 1 & 2 & 3 & 4 & 5 & 6 \\
\hline Value & 1.0848 & 1.3027 & 1.154 & 1.2711 & 1.42 & 1.537 \\
\hline Car & 7 & 8 & 9 & 10 & 11 & 12 \\
\hline Value & 1.1954 & 1.2927 & 1.2827 & 1.3999 & 1.41 & 1.5272 \\
\hline Car & 13 & 14 & 15 & 16 & 17 & 18 \\
\hline Value & 1.1855 & 1.6566 & 1.2828 & 1.39 & 0.9892 & 1.3026 \\
\hline Car & 19 & 20 & 21 & 22 & 23 & 24 \\
\hline Value & 1.16 & 1.404 & 1.378 & 1.3326 & 1.1754 & 1.2926 \\
\hline Car & 25 & 26 & 27 & & & \\
\hline Value & 1.3093 & 0.07 & 0.8209 & & & \\
\hline
\end{tabular}

\subsection{The analysis of the remaining category of customers}

As the exclusion of 12 constraints also excluded some customers, the whole procedure was repeated by claiming the previously-excluded constraints. The other constraints must be excluded to avoid contradictions. They were selected by the following optimisation problem:

$$
\begin{gathered}
\operatorname{Min} \Sigma y_{j k} \\
(j, k) \in E \\
\text { s.t } L_{k}+\Delta \leq L_{j} \quad(j, k) \in F \\
L_{k}+\Delta \leq L_{j}+M^{*} y_{j k} \quad(j, k) \in E \backslash F \\
L_{j}, L_{k} \geq 0 \\
\forall i:-1 \leq W_{i} \leq 1 \\
y_{j k} 0 \text { or } 1 \quad(j, k) \in E \backslash F
\end{gathered}
$$

The optimal solution suggested disregarding 16 pairs. Then another set of values of $\mathrm{W}_{i}$ can be determined, solving another optimisation problem of type (2). To find a robust solution for the second group of customers, it was enough to apply formula (3). The new vector $W_{i}^{*}$ and cars' values are computed in the following tables:

Table 8: The values of the factors for Customer Group 2

\begin{tabular}{|c|c|c|c|c|c|c|c|c|c|c|}
\hline $\mathbf{W}_{\mathbf{1}}^{*}$ & $\mathbf{W}_{\mathbf{2}}^{*}$ & $\mathbf{W}_{\mathbf{3}}^{*}$ & $\mathbf{W}_{\mathbf{4}}^{*}$ & $\mathbf{W}_{\mathbf{5}}^{*}$ & $\mathbf{W}_{\mathbf{6}}^{*}$ & $\mathbf{W}_{\mathbf{7}}^{*}$ & $\mathbf{W}_{\mathbf{8}}^{*}$ & $\mathbf{W}_{\mathbf{9}}^{*}$ & $\mathbf{W}_{\mathbf{1 0}}^{*}$ & $\mathbf{W}_{\mathbf{1 1}}^{*}$ \\
\hline 0.087 & -0.998 & -0.418 & -0.625 & 0.06 & -0.413 & -0.166 & -0.604 & -0.43 & 0.351 & -0.144 \\
\hline
\end{tabular}

\section{ESTIMATE OF THE CUSTOMERS' DEMAND AND ITS COMPARISON WITH THE CURRENT ASSORTMENT OF VEHICLES}

\subsection{Customers' choice based on microeconomics}

Tirole [27] suggested a linear utility function in the form: $\Theta * L-p$

$\Theta=$ the parameter that transforms quality to money,

$L=$ the value of the quality (real number) and

$\mathrm{P}=$ price

The general assumption in microeconomics is that $\Theta$, as a parameter, differs from customer to customer, and later it is considered as a random number in the model. In the solution of the models discussed below, the assumption suggested by Gabszewicz and Thisse [12] is used: the price is a quadratic function of the quality i.e.,

$$
p(L)=k L^{2} \text {, }
$$


Table 9: The scores of the cars for Customer Group 2

\begin{tabular}{|c|c|c|c|c|c|c|}
\hline Car & $\mathbf{1}$ & $\mathbf{2}$ & $\mathbf{3}$ & $\mathbf{4}$ & $\mathbf{5}$ & $\mathbf{6}$ \\
\hline Value & 0.9527 & 0.9691 & 0.8652 & 0.2394 & 0.7398 & 0.11406 \\
\hline Car & $\mathbf{7}$ & $\mathbf{8}$ & $\mathbf{9}$ & $\mathbf{1 0}$ & $\mathbf{1 1}$ & $\mathbf{1 2}$ \\
\hline Value & 0.2035 & 0.9743 & 0.8655 & 0.2397 & 0.745 & 0.1193 \\
\hline Car & $\mathbf{1 3}$ & $\mathbf{1 4}$ & $\mathbf{1 5}$ & $\mathbf{1 6}$ & $\mathbf{1 7}$ & $\mathbf{1 8}$ \\
\cline { 1 - 4 } Value & 0.2087 & 0.7693 & 0.9796 & 0.245 & 0.689 & 0.2597 \\
\cline { 1 - 4 } Car & $\mathbf{1 9}$ & $\mathbf{2 0}$ & $\mathbf{2 1}$ & $\mathbf{2 2}$ & $\mathbf{2 3}$ & $\mathbf{2 4}$ \\
\cline { 1 - 4 } Value & 0.2547 & 0.7532 & 1.1442 & 0.5545 & 0.8907 & 0.2649 \\
\cline { 1 - 4 } Car & $\mathbf{2 5}$ & $\mathbf{2 6}$ & $\mathbf{2 7}$ & & & \\
\cline { 1 - 4 } Value & 0.6645 & 1.2429 & 0.20487 & & &
\end{tabular}

where $k$ is a parameter. The necessary condition for a customer with parameter value $\Theta$ to buy car model A with quality $L_{a}$ and price $p^{a}$ is:

$$
\Theta L_{a}-p^{a} \geq 0 \text { or } \Theta \geq \frac{p^{a}}{L_{a}}
$$

Product $A$ is preferred to product $B$ if:

$$
\Theta L_{a}-p^{a} \geq \Theta L_{b}-p^{b}
$$

Assuming that $L_{a}>L_{b}$, the lower bound

$$
\Theta \geq \frac{p^{a}-p^{b}}{L_{a}-L_{b}}
$$

is obtained. Substituting the value of the price, this condition is equivalent to

$$
\Theta \geq \frac{p\left(L_{a}\right)-p\left(L_{b}\right)}{L_{a}-L_{b}}=\frac{k L_{a}{ }^{2}-k L_{b}{ }^{2}}{L_{a}-L_{b}}=k\left(L_{a}+L_{b}\right)
$$

\subsection{The tastes of the two customer groups}

The two customer groups determined in Sections 4.2 and 4.3 have different preferences. Customer Group 1's favourite factors were low price, large car size, high engine capacity, manual gearbox, and both the sedan and SUV body design. In contrast, a lack of interest in cheap cars, small car size, compact engine, hatchback design, automatic gearbox, and low consumption were the favourite factors for Customer Group 2.

\begin{tabular}{|c|c|c|c|c|c|c|c|c|c|c|c|c|c|}
\hline \multirow[b]{2}{*}{ 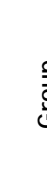 } & \multirow[b]{2}{*}{ 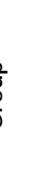 } & \multirow{3}{*}{$\begin{array}{l}\frac{n}{8} \\
\text { है } \\
\text { है } \\
52\end{array}$} & \multicolumn{2}{|c|}{ Gender } & \multicolumn{4}{|c|}{ Age } & \multicolumn{5}{|c|}{ Education status } \\
\hline & & & $\frac{\varrho}{\Sigma}$ & है & $\begin{array}{l}0 \\
\dot{m} \\
0 \\
\text { a }\end{array}$ & $\begin{array}{l}\frac{1}{7} \\
\frac{1}{m}\end{array}$ & $\begin{array}{l}8 \\
\vdots \\
0\end{array}$ & ஜ & $\begin{array}{l}5 \overline{8} \\
\overline{8} \frac{8}{8}\end{array}$ & $\begin{array}{l}\overline{8} \\
\overline{8} \\
\overline{8}\end{array}$ & $\frac{8}{8}$ & $\frac{\delta}{\frac{\delta}{q}}$ & $\begin{array}{l}\frac{1}{d} \\
\text { t. } \\
\sum\end{array}$ \\
\hline \multirow{2}{*}{1} & $\mathbf{Q}$ & & 35 & 12 & 14 & 21 & 10 & 2 & 6 & 9 & 16 & 12 & 6 \\
\hline & $\%$ & 54.17 & 74.47 & 25.53 & 29.79 & 44.68 & 21.28 & 4.26 & 12.24 & 18.37 & 32.65 & 24.49 & 12.24 \\
\hline \multirow{2}{*}{2} & $\mathbf{Q}$ & 42 & 29 & 13 & 23 & 14 & 3 & 0 & 1 & 6 & 13 & 20 & 2 \\
\hline & $\%$ & 43.75 & 69.05 & 30.95 & 57.5 & 35 & 7.5 & 0 & 2.38 & 14.29 & 30.95 & 47.62 & 4.76 \\
\hline
\end{tabular}

Based on the data obtained in the questionnaires, the main characteristics of the two groups of customers are summarised in Table 10.

Table 10: Portion and properties of groups 
As can be seen in Matrix 1 in the Appendix, 189 paired comparisons between the 27 cars were evaluated by 250 clients. Based on the questionnaire responses received from customers, 52 customers belonged exclusively to Group 1, 44 customers belonged exclusively to Group 2, and due to common taste in choosing between the two groups, 110 customers were placed at the intersection of the two groups, making a total of 206 persons. The results of the study cover 82.4 per cent of customers, which is seen as acceptable. Group 1 comprised men mostly, older members of the population (aged over 30), and people with lower levels of education. That finding is fully compatible with and justified by the vehicle type selected by each group.

\subsection{Estimation of the market shares of the car models}

As explained in Section 3.4, only models belonging to the same price category or to two consecutive categories are compared. According to the results from Sections 4.2 and 4.3, Group 1 and Group 2 contain 45 and 41 active constraints, respectively.

To gain a better understanding, pair comparison networks for both groups were drawn, as shown in Figures 1 and 2. Both of these networks contain all of the 27 cars, their pair comparisons, and their relationships.

The logic of the calculation to determine the market shares consists of the following steps. Each thread is considered a market when it has only the models included in the thread. Then, it is possible to apply the theory of vertical product differentiation explained by Tirole [27]. As $\theta$ is random, each market (i.e., each thread) has its own cumulative distribution function, which can be approximated by a partially linear function based on the inequalities (5). These cumulative distribution functions are transformed into a single united cumulative distribution function (UCDF). Models may be included in several threads. If so, then the union of these intervals is the selling interval of the model. This means that several models are sold at the same $\theta$ value, and it is necessary to determine the share of each model in the intervals of two consecutive break points of the UCDF.

The next step is to select a few directed paths in the network, such that they cover all 27 models. Figure 3 represents all of the mentioned threads for Customer Group 1. Each thread is represented by its cumulative distribution function under the assumption that there are no other cars on the market apart from those included in the thread. The breaking points are at the values obtained from the right-hand side of (4).

The first value $\Theta$ for all consecutive pairs in the 14 threads is defined by formula (5). According to (5), $\mathrm{k}$ is only a linear factor, and what is important is the ks products. Thus $k=1$ can be assumed without loss of generality.

For example, the thread (14-11-16-21-22-24-19) in Group 1 consists of seven cars, and their $\Theta$ values determine the break points of the cumulative distribution function.

In general, the slope of the cumulative distribution function of a thread between two break points is denoted by:

$$
\begin{aligned}
& m_{k, t}=\frac{a_{j-1, t}}{100 *\left(\theta_{k}-\theta_{k-1}\right)} \\
& m_{k, t}=\text { the slope of thread } t \text { to } \theta_{k} \text { from } \theta_{k-1}, t=1, \ldots 14 \text { and } k=1, \ldots, 56 \\
& a_{j, t}=\text { the weight of model } j \text { in threads } t \text { achieved by } a_{j, t}=\frac{L_{j}}{\sum_{j=1}^{27} L_{j}} \text {, where } L j \text { is defined } \\
& \text { as in Section 3, i.e., } L_{j}=\sum W_{i} P_{i j} \\
& \quad \theta_{k}=\text { the value of break point } k \text { achieved by } \theta_{k}=L_{j}+L_{j-1}
\end{aligned}
$$

Then the cumulative distribution functions' value (CDFV) of break points $\mathrm{k}$ in thread $\mathrm{t}$ is computed by:

$$
C D F V_{k, t}=C D F V_{k-1, t}+\left[m_{\mathrm{k}, \mathrm{t}} *\left(\Theta_{k}-\Theta_{k-1}\right)\right]
$$




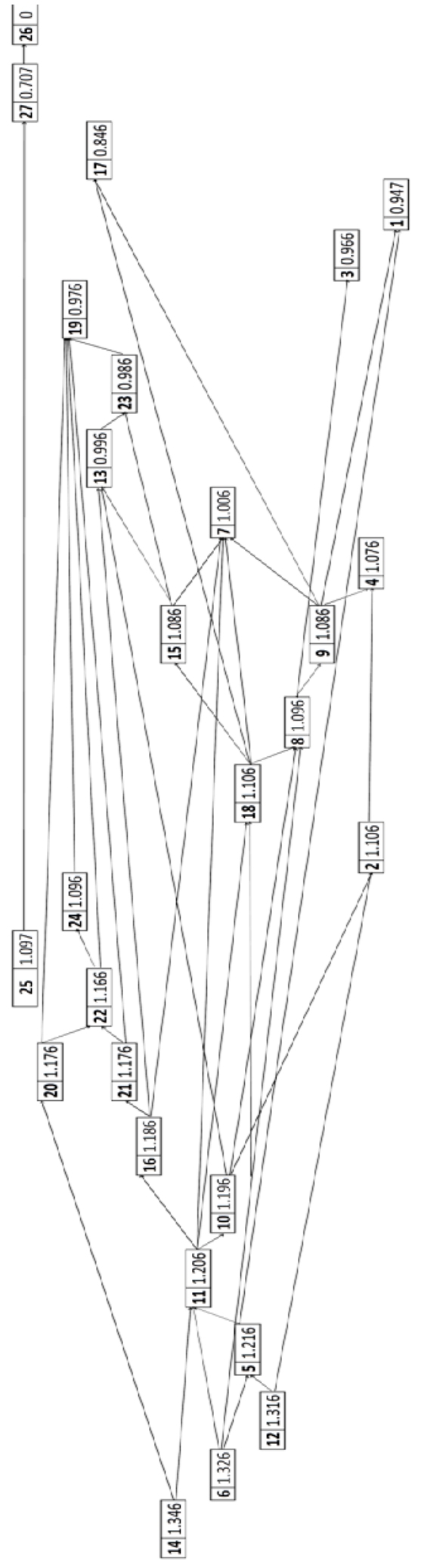

Figure 1: Car network for Group 1

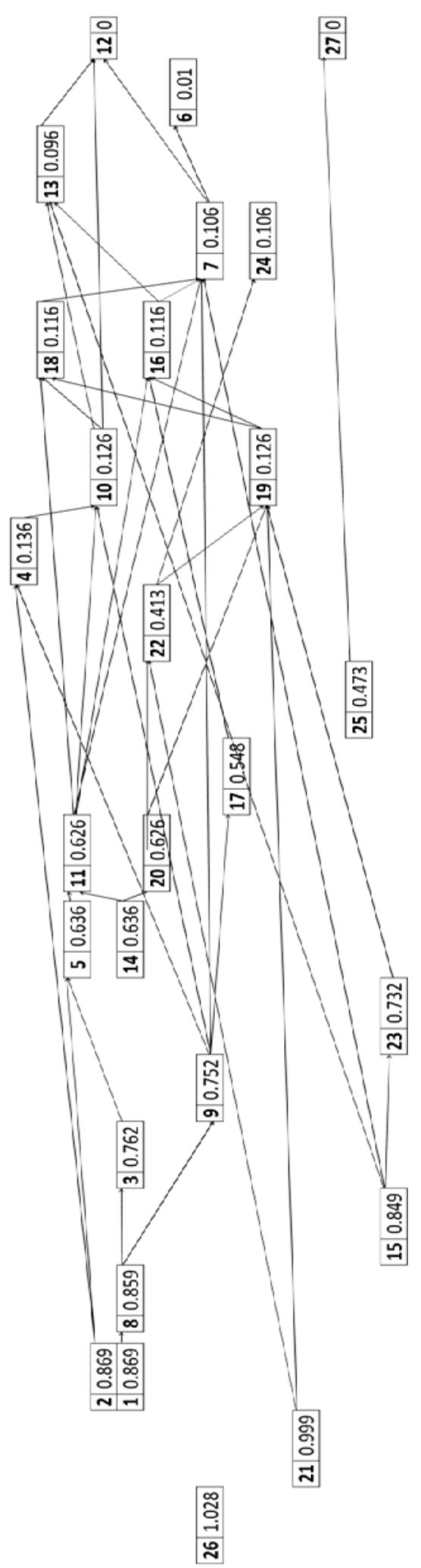

Figure 2: Car network for Group 2 


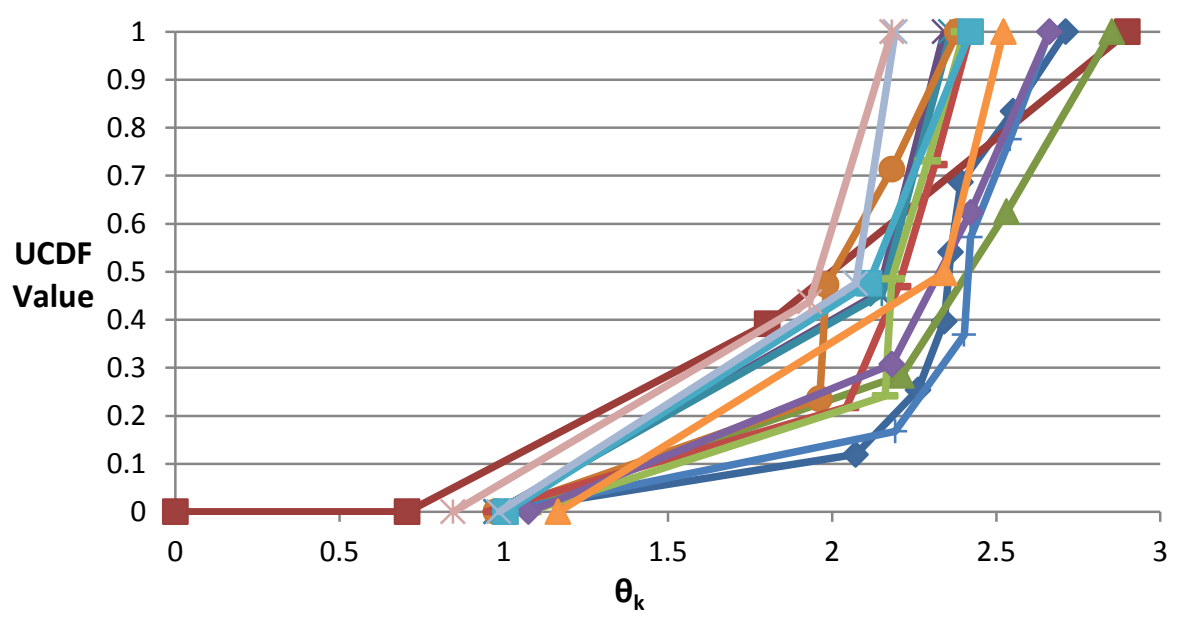

Figure 3: Selected threads to compute the unified cumulative distribution function for Group 1

The calculations were performed for all of the points in all of the threads; a sample result is shown in Table 11. Finally, the weight of each of the threads based on the existing cars' values in each thread was determined in order to estimate a unified cumulative distribution function (UCDF) that contains all 27 cars.

Table 11: Sample threads to compute UCDF

\begin{tabular}{|c|c|c|c|c|c|c|}
\hline Car & $\mathbf{L}_{\mathbf{j}}$ & $\mathbf{a}_{\mathbf{j}}$ & $\theta_{\mathbf{k}}$ & $\mathbf{m}_{\mathbf{k}}$ & $\mathrm{CDFV}_{\mathrm{k}}$ & $\mathbf{w}_{\mathrm{t}}$ \\
\hline 14 & 1.346 & 16.51 & 2.552 & 0.924 & 0.834 & \multirow{7}{*}{0.1676} \\
\hline 11 & 1.206 & 14.79 & 2.392 & 4.850 & 0.686 & \\
\hline 16 & 1.186 & 14.55 & 2.362 & 7.215 & 0.541 & \\
\hline 21 & 1.176 & 14.43 & 2.342 & 1.788 & 0.397 & \\
\hline 22 & 1.166 & 14.3 & 2.262 & 0.707 & 0.254 & \\
\hline 24 & 1.096 & 13.44 & 2.072 & 0.109 & 0.119 & \\
\hline 19 & 0.976 & 11.97 & 0.9761 & 0 & 0 & \\
\hline
\end{tabular}

To obtain the UCDF values for all the break points in Figure 3, first, as in Table 11, the computation for all the selected threads was made. Next, the break points were sorted by descending value in a different table, with related slopes and threads' weight. The UCDF was calculated by the following formula:

$$
\mathrm{UCDF}_{\mathrm{k}}=\mathrm{UCDF}_{\mathrm{k}-1}+\left(\Theta_{\mathrm{k}}-\Theta_{\mathrm{k}-1}\right) \sum_{k, t=1}^{56,14} m_{k, t} w_{t}
$$

Based on Figure 3 and considering formula (5), 56 break points were used to compute their UCDF values. These included 45 paired comparisons in Group 1 plus seven $\theta$ values for cars $(26,19,17,7,3,4,1)$ on the right-hand side of threads that are equal to $L_{j}$, and four models $(25,14,6,12)$ on the left-hand side of threads for which $\theta$ is estimated by $2 \mathrm{~L}_{\mathrm{j}}+$ $\mathrm{L}_{\mathrm{j}-1}$. Here, $w_{t}$ is the weight of threads, and it is determined by dividing the summation of the values $\left(L_{j} S\right)$ of the existing models in the thread by the summation of all the threads' value. Further on, $\theta_{\mathrm{k}}>\theta_{\mathrm{k}-1}$ and $\theta_{\mathrm{k}-1}$ are the previous break points in the united set of all break points of the threads relative to $\theta_{\mathrm{k}}$.

Note 1: To compute $\mathrm{UCDF}_{\mathrm{k}}, \sum_{k, t=1}^{56,14} m_{k, t} w_{t}$ in the interval $\left[\theta_{\mathrm{k}-1}, \theta_{\mathrm{k}}\right]$ is the summation of the multiplication of the slope of the thread from the previous break point on the same thread and the last break points on the other threads by the current break point, in related weights of the threads. 
Note 2: The initial UCDF value is zero, and the last break point UCDF value based on the above formula is 1 .

Note 3: If any of the previous break points are the last point in the related thread, it does not affect the next break point's UCDF value.

After defining the UCDF value by generating 100,000 random numbers on $[0,1]$, the probability of occurrence of each interval of UCDF is determined. The probability of an interval is estimated by the relative number of cases that fell into the interval.

Due to the overlap of vehicles' intervals, several cars were located in each interval of consecutive break points of the UCDF. The weight of a model was determined in each of the intervals. The market share of the model is the sum of the shares of the model in the intervals weighted by the probability of the intervals.

$$
C_{j}=\sum_{j, k=1}^{27,56} I_{k} P_{j, k}
$$

$C_{j}=$ car model $j$ predicted market share for all 27 models

$I_{k}=$ probability of interval $k(\mathrm{k}=1,2, \ldots, 56)$

$P_{j, k}=$ share of model $j$ in the interval $k$ computed by $\frac{L_{j}}{\sum_{j, k=1}^{27,56} L_{J, K}}$

The computation is repeated for Group 2 with 51 intervals in formula (6). The average market share of all 27 models is achieved, and is shown in Table 12.

\subsection{Empirical results}

According to Table 13, the first sign of deflection for current products is desirable from a consumer's perspective. First of all, it is worth mentioning that 45 per cent of the total market belongs to cars that are not currently in the production basket. The car market share for the 15 existing models, the shares of the models produced in the last five years, and the difference from the value predicted by considering the contribution of each of the groups, are shown in Table 13.

\section{DISCUSSION}

To confirm the difference between the taste of the clients and the production status, about 70 per cent of the current production belonging to the five models $(4,12,17,18$, and 24) has the same size (large) and body design (sedan) (see Figure 14). In addition, 92 per cent of the negative differences correspond to six models (206-V5, 6, 207, and L90 (E1, E2)), which hold 55.77 per cent of the predicted car shares.

In Table 14, the four models (14, 19, 20, and 21) that have a 31.28 per cent share are in the small, hatchback, and full options car category. This indicates that, although customers desire to buy this type of car, it has only a 3.59 per cent share of the production, which shows that this type of car has been neglected in the market. This reveals that the market demand could be served if greater production capacity were allocated to these models.

After IKCO abandoned Peykan with its 10.86 per cent market share in 2006, the Renault L90 was supposed to be a suitable alternative in the IKCO product basket. However, due to limitations in supplying parts for this car, the operational planning of production was not fulfilled. A significant change in the product basket therefore did not take place, and the most required model accounts for the greatest difference between production and demand, which is 21.87 per cent. 
Table 12: 27 cars' market share for both groups

\begin{tabular}{|c|c|c|c|c|}
\hline Car number & Car name & Group 1 & Group 2 & Estimated market share \\
\hline 1 & Potential & $6.27 \%$ & $3.03 \%$ & $4.48 \%$ \\
\hline 2 & Renault L90(E0) & $7.95 \%$ & $7.38 \%$ & $7.63 \%$ \\
\hline 3 & Potential & $4.66 \%$ & $4.78 \%$ & $4.72 \%$ \\
\hline 4 & ROA & $6.18 \%$ & $1.78 \%$ & $3.75 \%$ \\
\hline 5 & Potential & $0.45 \%$ & $1.80 \%$ & $1.20 \%$ \\
\hline 6 & Peugeot 405(GLI) & $2.84 \%$ & $0.30 \%$ & $1.44 \%$ \\
\hline 7 & Peugeot 206(V2) & $7.53 \%$ & $1.97 \%$ & $4.45 \%$ \\
\hline 8 & Renault L90(E1) & $7.88 \%$ & $0.76 \%$ & $3.94 \%$ \\
\hline 9 & Potential & $0.16 \%$ & $2.47 \%$ & $1.44 \%$ \\
\hline 10 & Peugeot 206-SD(V8) & $3.78 \%$ & $1.07 \%$ & $2.28 \%$ \\
\hline 11 & Potential & $3.63 \%$ & $7.24 \%$ & $5.63 \%$ \\
\hline 12 & Peugeot 405(GLX) & $2.75 \%$ & $0.02 \%$ & $1.24 \%$ \\
\hline 13 & Peugeot 206(V3) & $1.96 \%$ & $1.02 \%$ & $1.44 \%$ \\
\hline 14 & Peugeot 207-M & $1.06 \%$ & $4.80 \%$ & $3.13 \%$ \\
\hline 15 & Renault L90(E2) & $0.99 \%$ & $6.92 \%$ & $4.27 \%$ \\
\hline 16 & Potential & $0.49 \%$ & $1.67 \%$ & $1.15 \%$ \\
\hline 17 & SAMAND & $3.22 \%$ & $9.55 \%$ & $6.72 \%$ \\
\hline 18 & SAMAND-LX & $3.27 \%$ & $1.67 \%$ & $2.39 \%$ \\
\hline 19 & Peugeot 206(V5) & $6.19 \%$ & $2.09 \%$ & $3.92 \%$ \\
\hline 20 & Peugeot 206(V6) & $3.65 \%$ & $3.37 \%$ & $3.50 \%$ \\
\hline 21 & Peugeot 207-A & $0.65 \%$ & $13.14 \%$ & $7.56 \%$ \\
\hline 22 & Peugeot 206-SD(V19) & $2.36 \%$ & $7.76 \%$ & $5.35 \%$ \\
\hline 23 & Potential & $0.80 \%$ & $10.60 \%$ & $6.22 \%$ \\
\hline 24 & Peugeot Pars & $4.01 \%$ & $1.01 \%$ & $2.35 \%$ \\
\hline 25 & Suzuki Kizashi & $13.96 \%$ & $3.65 \%$ & $8.26 \%$ \\
\hline 26 & Suzuki Vitara & $0.19 \%$ & $0.11 \%$ & $0.15 \%$ \\
\hline 27 & Potential & $3.10 \%$ & $0.02 \%$ & $1.40 \%$ \\
\hline
\end{tabular}

Table 13: Existing cars' market share for both groups

\begin{tabular}{|c|c|c|c|c|c|c|}
\hline Car number & Car name & Group 1 & Group 2 & Avg. & History & Def. \\
\hline 4 & ROA & $14.01 \%$ & $1.98 \%$ & $8.49 \%$ & $9.24 \%$ & $0.75 \%$ \\
\hline 7 & Peugeot 206(V2) & $12.26 \%$ & $2.55 \%$ & $7.81 \%$ & $12.77 \%$ & $4.96 \%$ \\
\hline $8,15 *$ & Renault L90(E1,E2) & $14.42 \%$ & $36.40 \%$ & $24.49 \%$ & $2.62 \%$ & $-21.87 \%$ \\
\hline 10 & Peugeot 206-SD(V8) & $3.52 \%$ & $2.30 \%$ & $2.96 \%$ & $4.08 \%$ & $1.12 \%$ \\
\hline 12 & Peugeot 405(GLX) & $11.05 \%$ & $0.11 \%$ & $6.04 \%$ & $32.62 \%$ & $26.58 \%$ \\
\hline 14 & Peugeot 207(M) & $8.78 \%$ & $11.69 \%$ & $10.12 \%$ & $0.76 \%$ & $-9.36 \%$ \\
\hline 17 & SAMAND & $5.32 \%$ & $10.02 \%$ & $7.48 \%$ & $3.12 \%$ & $-4.36 \%$ \\
\hline 18 & SAMAND-LX & $2.53 \%$ & $2.80 \%$ & $2.65 \%$ & $13.92 \%$ & $11.27 \%$ \\
\hline 19 & Peugeot 206(V5) & $8.39 \%$ & $3.69 \%$ & $6.24 \%$ & $0.98 \%$ & $-5.25 \%$ \\
\hline 20 & Peugeot 206(V6) & $8.82 \%$ & $3.27 \%$ & $6.28 \%$ & $1.24 \%$ & $-5.04 \%$ \\
\hline 21 & Peugeot 207(A) & $2.86 \%$ & $15.50 \%$ & $8.65 \%$ & $0.61 \%$ & $-8.04 \%$ \\
\hline 22 & Peugeot 206-SD(V19) & $4.75 \%$ & $7.78 \%$ & $6.14 \%$ & $6.18 \%$ & $0.05 \%$ \\
\hline 24 & Peugeot Pars & $3.27 \%$ & $1.57 \%$ & $2.49 \%$ & $11.08 \%$ & $8.59 \%$ \\
\hline 26 & Suzuki Vitara & $0.02 \%$ & $0.34 \%$ & $0.17 \%$ & $0.77 \%$ & $0.60 \%$ \\
\hline
\end{tabular}

* There are no separate data for these two cars. 
Table 14: Negative model differences

\begin{tabular}{|c|c|c|c|c|c|c|}
\hline Car number & Car name & Group 1 & Group 2 & Ave. & History & Def. \\
\hline 8,15 & Renault L90(E1,E2) & $14.42 \%$ & $36.40 \%$ & $24.49 \%$ & $2.62 \%$ & $-21.87 \%$ \\
\hline 14 & Peugeot 207(M) & $8.78 \%$ & $11.69 \%$ & $10.12 \%$ & $0.76 \%$ & $-9.36 \%$ \\
\hline 19 & Peugeot 206(V5) & $8.39 \%$ & $3.69 \%$ & $6.24 \%$ & $0.98 \%$ & $-5.25 \%$ \\
\hline 20 & Peugeot 206(V6) & $8.82 \%$ & $3.27 \%$ & $6.28 \%$ & $1.24 \%$ & $-5.04 \%$ \\
\hline 21 & Peugeot 207(A) & $2.86 \%$ & $15.50 \%$ & $8.65 \%$ & $0.61 \%$ & $-8.04 \%$ \\
\hline 17 & SAMAND & $5.32 \%$ & $10.02 \%$ & $7.48 \%$ & $3.12 \%$ & $-4.36 \%$ \\
\hline
\end{tabular}

\section{CONCLUSION}

This paper elaborates a method for estimating customers' behaviour through the utility function based on the various factors of a product. Then using Tirole's [27] and Gabszewicz and Thisse's [12] formulas, the market share of all the vehicles was investigated. Considering the history of car sales over the past five years, and compared with the value predicted by the existing cars' market share, a significant difference was detected between the current productions of Iran Khodro Co. and a product assortment ideally adapted to the customers. The results generally confirm the paper by Rahmati and Yousefi [2], which claimed that "the Iranian automobile market is an example of an oligopolistic differentiated products market with two domestic manufacturers and a number of importing firms". With this feature, the estimated difference between the producer and the consumer is provided through simulation techniques.

This article has provided a method for identifying customer behaviour based on choices among options consisting of a set of qualitative and quantitative factors. The number and type of factors and vehicles can be changed to evaluate the market share of any kind of product, which could include current products, products in the launch period, or products that need to be introduced into the market.

The production profit estimated by a company can justify the difference between the market shares of existing products and the predicted shares; because these data are confidential, a comparison of the existing and potential profits is not possible. The reduction of current customs duties on imported cars, or the entry of other automobilemakers into the Iranian car market, will cause market polarisation. The method presented in this paper can be used, therefore, to prevent auto market share decline and increase profitability through achieving customer satisfaction.

\section{REFERENCES}

[1] Flavio , A. M., \& Rangel, D. L. (2008). Determining the utility functions of criteria used in the evaluation of real estate. Int. J. Production Economics, 420-426.

[2] Rahmati, M., \& Yousefi, S. (2011, August ). Demand estimation for the Iranian automobile industry. The Quarterly Review of Economics and Finance, 53(3), 277-284.

[3] Abounoori, E., \& Rezvani, A. (2012). Using Hedonic Prices to Estimate Quality Changes concerning Iranian Automobile Market. Iranian J ournal of Economic Studies, 1(1), 1-12.

[4] Asgharpour, A., Hoseini, H., \& Azizi, S. (2003). Identify and ordering the factors influence the Iran Khodro CO. with AHP. J ournal of management message, 7(8), 47-74.

[5] Berger, J. O. (1985). Utility and Loss. Statistical Decision Theory and Bayesian Analysis (2nd ed.).

[6] Botha, G. J., Kruger, P. S., \& Vries, M. d. (2012). Enhancing Customer Experience Through Business Process Improvement:An Application Of The Enhanced Customer Experience Framework (ECEF). South African J ournal of Industrial Engineering, 23(2), 39-56.

[7] Chojnacki, K. (2000). Relationship Marketing at Volkswagen. Relationship Marketing, 49-58.

[8] Cubbin, J. S. (1975, February). Quality Change and Pricing Behaviour in the United Kingdom Car Industry. Economica, London School of Economics and Political Science, 42(165), 43-58.

[9] Danaher, P. J. (1997). Using conjoint analysis to determine the relative importance of service 
attributes measured in customer satisfaction surveys. J ournal of Retailing, 73(2).

[10] Dizaji, S. F. (1999). Microeconomic Theory. Tehran: Bazargani co.

[11] Economics for the Environment Consultancy (EFTEC). (2008). Demand for Cars and their Attributes. Transport, London.

[12] Gabszewicz, J. J., \& Thisse, J. F. $(\mathbf{1 9 7 9}, 6$ 30). Price competition, quality and income disparities. (A. Press, Ed.) 20(3), 340-359.

[13] Gaby, O. S., Ouwersloot, H., Limmink, J., \& Semeijn, J. (2003). Consumers' trade- off between relationship, service package and price: An empirical study in the car industry. European J ournal of Marketing, 37 (1/2), $219-242$.

[14] Goff, B. G., Boles, J. S., Bellenger, D. N., \& Stojack, C. (1997, Summer ). The influence of salesperson selling behaviors on customer satisfaction with products. J ournal of Retailing, 73(2), 171-183.

[15] Hayes, B. E. (1998). Measuring customer satisfaction: survey design, use, and statistical analysis methods (Second Edition ed.). ASQ Quality Press.

[16] J onathan, E., \& Ingersoll, J. (1987). Theory of Financial Decision Making. Rowman and Littlefield.

[17] J üttner, U., \& Wehrli, H. P. (1994). Competitive Advantage: Merging Marketing and the Competence-based Perspective. J ournal of Business \& Industrial Marketing, 9(4), 42 - 53.

[18] LaBarbera, P. A., \& Mazursky, D. (1983). A longitudinal assessment of consumer satisfaction/ dissatisfaction. J ournal of Marketing Research, 20, 393-404.

[19] Lancaster, K. J. (1966Apr). Consumer demand: a new approach. Chicago J ournals, 74(2), 132157.

[20] Lawrence, A., Kenneth , R. E., Cowles, D., Crosby, L., \& , KR Evans, D Cowles. (1990). Relationship quality in services selling: An Interpersonal Influence perspective. Journal of Marketing, 54, 68-81.

[21] Marr, S. L., \& Crosby, L. A. (1992). Customer satisfaction measurement. Chicago: American Marketing Association.

[22] Marshall, A. (1920). Principles of Economics (8th ed.). London: Macmillan and Co., Ltd.

[23] Murray, J., \& Sarantis, N. (1999). Quality, User Cost, Forward-Looking Behavior, and the Demand for Cars in the UK. (J. Murray, \& N. Sarantis, Eds.) J ournal of Economics and Business, $51,237-258$.

[24] Ostrom, A., \& lacobucci, D. (1995, January). Consumer Trade-Offs and the Evaluation of Services. J ournal of Marketing, 59, 17-28.

[25] Richheld, J., \& Illingworth, D. (1991). Relationship p Marketing: Pursuing the Perfect Person-toPerson Relationship. J ournal of Services Marketing, 5(4), 49- 52.

[26] Roscino, A., \& Pollice, A. (2004). A statistical analysis of the customer satisfaction with car dealers. Applied Stochastic Models in Business and Industry, 20(3), 281-289.

[27] Tirole, J. (1988). The theory of industrial organization. Cambridge, MA:MITPress. 


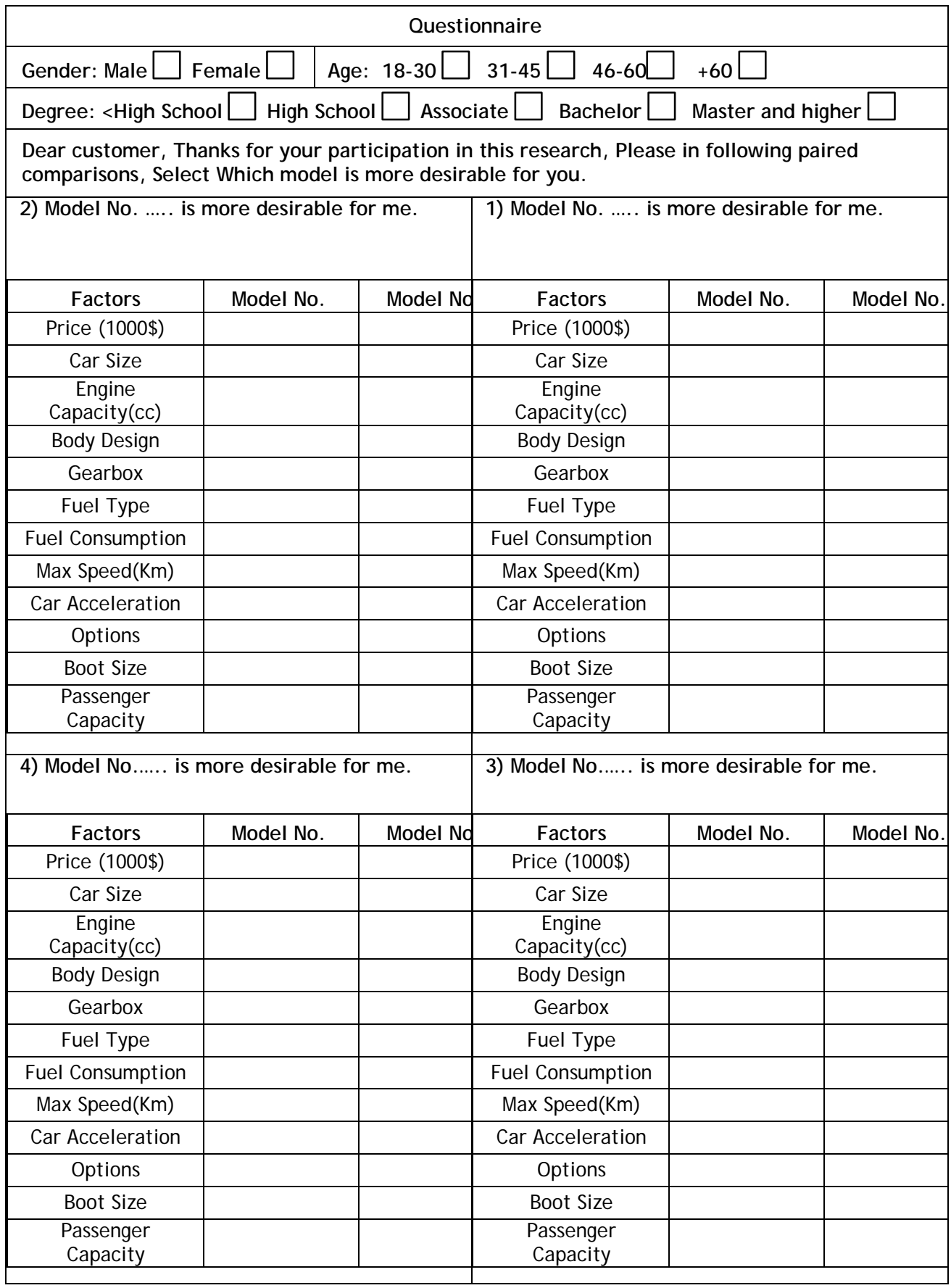




\begin{tabular}{|c|c|c|c|c|c|c|c|c|c|c|c|c|c|c|c|c|c|c|c|c|c|c|c|c|c|c|c|}
\hline & 1 & 2 & 3 & 4 & 5 & 6 & 7 & 8 & 9 & 10 & 11 & 12 & 13 & 14 & 15 & 16 & 17 & 18 & 19 & 20 & 21 & 22 & 23 & 24 & 25 & 26 & 27 \\
\hline 1 & 0 & 1 & 1 & 1 & 1 & 1 & 1 & 1 & 1 & 1 & 1 & 1 & 0 & 0 & 0 & 0 & 0 & 0 & 0 & 0 & 0 & 0 & 0 & 0 & 0 & 0 & 0 \\
\hline 2 & 1 & 0 & 1 & 1 & 1 & 1 & 1 & 1 & 1 & 1 & 1 & 1 & 0 & 0 & 0 & 0 & 0 & 0 & 0 & 0 & 0 & 0 & 0 & 0 & 0 & 0 & 0 \\
\hline 3 & 1 & 1 & 0 & 1 & 1 & 1 & 1 & 1 & 1 & 1 & 1 & 1 & 0 & 0 & 0 & 0 & 0 & 0 & 0 & 0 & 0 & 0 & 0 & 0 & 0 & 0 & 0 \\
\hline 4 & 1 & 1 & 1 & 0 & 1 & 1 & 1 & 1 & 1 & 1 & 1 & 1 & 0 & 0 & 0 & 0 & 0 & 0 & 0 & 0 & 0 & 0 & 0 & 0 & 0 & 0 & 0 \\
\hline 5 & 1 & 1 & 1 & 1 & 0 & 1 & 1 & 1 & 1 & 1 & 1 & 1 & 0 & 0 & 0 & 0 & 0 & 0 & 0 & 0 & 0 & 0 & 0 & 0 & 0 & 0 & 0 \\
\hline 6 & 1 & 1 & 1 & 1 & 1 & 0 & 1 & 1 & 1 & 1 & 1 & 1 & 0 & 0 & 0 & 0 & 0 & 0 & 0 & 0 & 0 & 0 & 0 & 0 & 0 & 0 & 0 \\
\hline 7 & 1 & 1 & 1 & 1 & 1 & 1 & 0 & 1 & 1 & 1 & 1 & 1 & 1 & 1 & 1 & 1 & 1 & 1 & 0 & 0 & 0 & 0 & 0 & 0 & 0 & 0 & 0 \\
\hline 8 & 1 & 1 & 1 & 1 & 1 & 1 & 1 & 0 & 1 & 1 & 1 & 1 & 1 & 1 & 1 & 1 & 1 & 1 & 0 & 0 & 0 & 0 & 0 & 0 & 0 & 0 & 0 \\
\hline 9 & 1 & 1 & 1 & 1 & 1 & 1 & 1 & 1 & 0 & 1 & 1 & 1 & 1 & 1 & 1 & 1 & 1 & 1 & 0 & 0 & 0 & 0 & 0 & 0 & 0 & 0 & 0 \\
\hline 10 & 1 & 1 & 1 & 1 & 1 & 1 & 1 & 1 & 1 & 0 & 1 & 1 & 1 & 1 & 1 & 1 & 1 & 1 & 0 & 0 & 0 & 0 & 0 & 0 & 0 & 0 & 0 \\
\hline 11 & 1 & 1 & 1 & 1 & 1 & 1 & 1 & 1 & 1 & 1 & 0 & 1 & 1 & 1 & 1 & 1 & 1 & 1 & 0 & 0 & 0 & 0 & 0 & 0 & 0 & 0 & 0 \\
\hline 12 & 1 & 1 & 1 & 1 & 1 & 1 & 1 & 1 & 1 & 1 & 1 & 0 & 1 & 1 & 1 & 1 & 1 & 1 & 0 & 0 & 0 & 0 & 0 & 0 & 0 & 0 & 0 \\
\hline 13 & 0 & 0 & 0 & 0 & 0 & 0 & 1 & 1 & 1 & 1 & 1 & 1 & 0 & 1 & 1 & 1 & 1 & 1 & 1 & 1 & 1 & 1 & 1 & 1 & 0 & 0 & 0 \\
\hline 14 & 0 & 0 & 0 & 0 & 0 & 0 & 1 & 1 & 1 & 1 & 1 & 1 & 1 & 0 & 1 & 1 & 1 & 1 & 1 & 1 & 1 & 1 & 1 & 1 & 0 & 0 & 0 \\
\hline 15 & 0 & 0 & 0 & 0 & 0 & 0 & 1 & 1 & 1 & 1 & 1 & 1 & 1 & 1 & 0 & 1 & 1 & 1 & 1 & 1 & 1 & 1 & 1 & 1 & 0 & 0 & 0 \\
\hline 16 & 0 & 0 & 0 & 0 & 0 & 0 & 1 & 1 & 1 & 1 & 1 & 1 & 1 & 1 & 1 & 0 & 1 & 1 & 1 & 1 & 1 & 1 & 1 & 1 & 0 & 0 & 0 \\
\hline 17 & 0 & 0 & 0 & 0 & 0 & 0 & 1 & 1 & 1 & 1 & 1 & 1 & 1 & 1 & 1 & 1 & 0 & 1 & 1 & 1 & 1 & 1 & 1 & 1 & 0 & 0 & 0 \\
\hline 18 & 0 & 0 & 0 & 0 & 0 & 0 & 1 & 1 & 1 & 1 & 1 & 1 & 1 & 1 & 1 & 1 & 1 & 0 & 1 & 1 & 1 & 1 & 1 & 1 & 0 & 0 & 0 \\
\hline 19 & 0 & 0 & 0 & 0 & 0 & 0 & 0 & 0 & 0 & 0 & 0 & 0 & 1 & 1 & 1 & 1 & 1 & 1 & 0 & 1 & 1 & 1 & 1 & 1 & 1 & 1 & 1 \\
\hline 20 & 0 & 0 & 0 & 0 & 0 & 0 & 0 & 0 & 0 & 0 & 0 & 0 & 1 & 1 & 1 & 1 & 1 & 1 & 1 & 0 & 1 & 1 & 1 & 1 & 1 & 1 & 1 \\
\hline 21 & 0 & 0 & 0 & 0 & 0 & 0 & 0 & 0 & 0 & 0 & 0 & 0 & 1 & 1 & 1 & 1 & 1 & 1 & 1 & 1 & 0 & 1 & 1 & 1 & 1 & 1 & 1 \\
\hline 22 & 0 & 0 & 0 & 0 & 0 & 0 & 0 & 0 & 0 & 0 & 0 & 0 & 1 & 1 & 1 & 1 & 1 & 1 & 1 & 1 & 1 & 0 & 1 & 1 & 1 & 1 & 1 \\
\hline 23 & 0 & 0 & 0 & 0 & 0 & 0 & 0 & 0 & 0 & 0 & 0 & 0 & 1 & 1 & 1 & 1 & 1 & 1 & 1 & 1 & 1 & 1 & 0 & 1 & 1 & 1 & 1 \\
\hline 24 & 0 & 0 & 0 & 0 & 0 & 0 & 0 & 0 & 0 & 0 & 0 & 0 & 1 & 1 & 1 & 1 & 1 & 1 & 1 & 1 & 1 & 1 & 1 & 0 & 1 & 1 & 1 \\
\hline 25 & 0 & 0 & 0 & 0 & 0 & 0 & 0 & 0 & 0 & 0 & 0 & 0 & 0 & 0 & 0 & 0 & 0 & 0 & 1 & 1 & 1 & 1 & 1 & 1 & 0 & 1 & 1 \\
\hline 26 & 0 & 0 & 0 & 0 & 0 & 0 & 0 & 0 & 0 & 0 & 0 & 0 & 0 & 0 & 0 & 0 & 0 & 0 & 1 & 1 & 1 & 1 & 1 & 1 & 1 & 0 & 1 \\
\hline 27 & 0 & 0 & 0 & 0 & 0 & 0 & 0 & 0 & 0 & 0 & 0 & 0 & 0 & 0 & 0 & 0 & 0 & 0 & 1 & 1 & 1 & 1 & 1 & 1 & 1 & 1 & 0 \\
\hline
\end{tabular}

*Note: 1 means a paired comparison between two cars and 0 means not. 